Technical Aspects of Critical Materials Use by the Steel Industry

Volume I: Summary Report

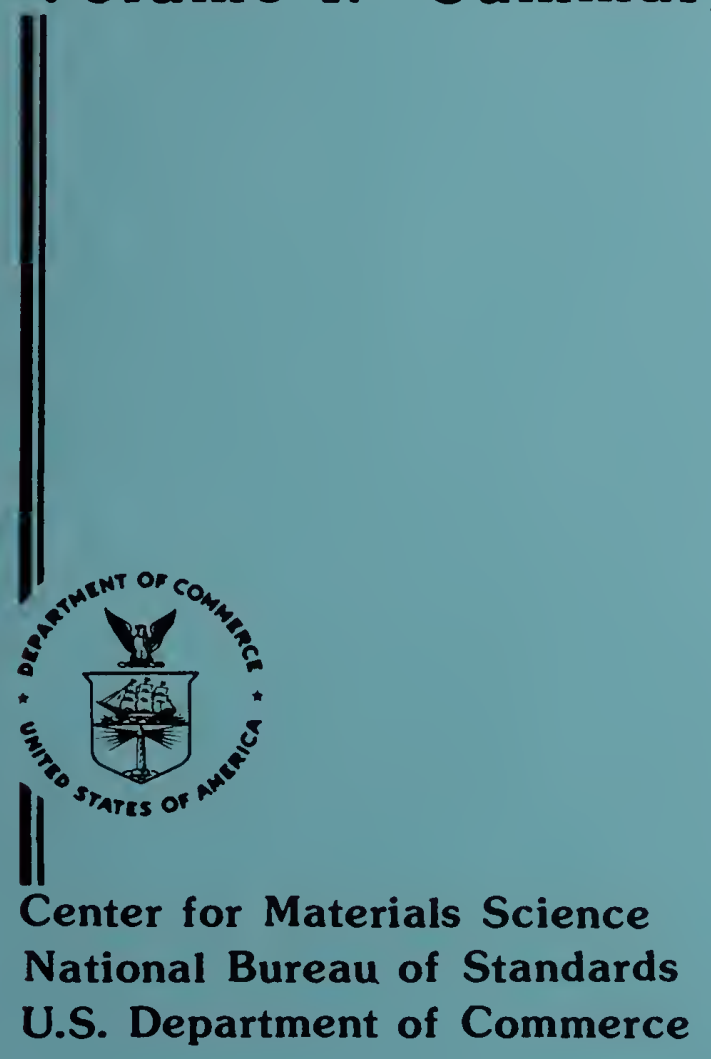



NBSIR 83-2679-1

\section{Technical Aspects of Critical Materials Use by the Steel Industry}

\section{Volume I: Summary Report}

Robert Mehrabian John D. McKinley Bruce W. Steiner

Kirit J. Bhansali

April 1983

U.S. Department of Commerce, Malcolm Baldrige, Secretary National Bureau of Standards, Ernest Ambler, Director 



\section{Preface}

This report was prepared by the Center for Materials Science (CMS) for the Department of Commerce as a technical chapter in the Department's study of "Critical Materials Requirements of the U.S. Steel Industry." That study resulted from a Commerce Department responsibility under the "National Materials and Minerals Policy, Research and Development Act of 1980," (PL 96-479) to "continually----identify and assess---(materials needs) cases as necessary to ensure an adequate and stable supply of materials to meet national security, economic well being, and industrial production needs."

This report reviews technical opportunities for research in process improvement and in alternative materials development that would reduce U.S. dependency on critical materials.

The advanced technologies reviewed here, in addition to their implications for critical materials conservation, represent trends leading to better quality and lower cost steel products. Thus, they may also contribute positively to the industry's more immediate concern for improved markets.

The report draws extensively on material presented at a public workshop sponsored jointly by the National Bureau of Standards, Bureau of Mines, and the Army Research Office. The workshop, "Critical Materials Requirements for Steels of the Future; Conservation and Substitution for Chromium," was held at Vanderbilt University, October 4-7, 1982; it featured 50 presentations by technical authorities from steel producing and using industries. The Proceedings of that Workshop are published as Volume II of this Report. 


\section{Contents}

VOLUME I: SUMMARY REPORT

EXECUTIVE SUMMARY. ................ . . iX

INTRODUCTION . . . . . . . . . . . . . . . . 1

PROCESSING . . . . . . . . . . . . . . 6

Current Economic Status of the Industry . . . . 6

Technical Status of the Three Major Sectors . . . 7

Technical Developments in Processing . . . . . 9

Continuous Casting ........... . 9

Primary Melting and Refining Processes . . . 10

Real-Time Control ......... . 13

Near Net Shape Technology . . . . . . 15

Surface Modification ........... . 16

Steel Plant Refractories . . . . . . . 18

Import Implications of Advanced Technical

Developments . . . . . . . . . . . 19

Recycling................ . . 20

SUBSTITUTION . . . . . . . . . . . . . 23

Chromium Functions in Steel . . . . . . . . 24

Substitution Options for Chromium in Corrosion and Oxidation Resistant Stainless Steels . . . 24

Substitution Options for Chromium in Structural

Alloy Steels ............. . 29

INSTITUTIONAL FACTORS . . . . . . . . . 32

Specifications . . . . . . . . . . 32

Qualification............ . . . 32

Composition of the Natural Defense Stockpile . . 33

Research. . . . . . . . . . . . . 34

CRITICAL MATERIALS AND PRODUCTIVITY. . . . . . . . 37

REFERENCES . . . . . . . . . . . . . . 39 
VOLUME II A: Proceedings of a Public Workshop; "Trends in Critical Materials Requirements for Steels of the Future; Conservation and Substitution Technology for Chromium".

\section{Significance of the Workshop}

CRITICAL MATERIALS NEEDS FOR FUTURE STEELS AND THE CHALLENGE OF THE CHROMIUM SITUATION, Allen G. Gray, Workshop Organizer and Chairman; Vanderbilt University and American Society for Metals.

\section{Workshop Keynote Session}

INDUSTRIAL LIFE WITHOUT CHROMIUM-TECHNOLOGICAL CHALLENGES, Arden L. Bement, Jr., TRW Inc.

POTENTIAL FOR CRITICAL MATERIALS CONSERVATION IN THE INTEGRATED STEEL INDUSTRY, Gordon H. Geiger, Chase Manhattan Bank.

POTENTIAL AREAS FOR CHROMIUM CONSERVATION IN STAINLESS STEELS, R. A. LuTa, Consultant.

THE VALUE OF GENERIC TECHNOLOGY: SUBSTITUTION BASED ON HARDENABILITY, Dale H. Breen, Gear Research Institute.

Users' Views on Steels Needed For The Future Technological Trends on Critical Materials Required For These Steels

TRENDS AND NEEDS FOR FUTURE STEELS IN BUILDINGS AND BRIDGES, Lewis Brunner, American Institute of Steel Construction.

THE MATERIALS USE AND RESEARCH OUTLOOK IN THE RAILWAY INDUSTRY, William J. Harris, Association of American Railroads.

TRENDS AND NEEDS FOR FUTURE AUTOMOTIVE STEELS, George H. Robinson, General Motors Corporation.

CATERPILLAR TRACTOR CO. VIEWS ON STEELS NEEDED FOR FUTURE APPLICATIONS, Dennis B. O'Neil, Caterpillar Tractor Co.

CHEMICAL EQUIPMENT - USER'S VIEWS ON STEELS NEEDED FOR THE FUTURE, Edward A. Kachik, Materials Technology Institute.

ELECTRIC UTILITY VIEW OF THE USE OF CRITICAL METALS IN STEEL,

Robert I. Jaffee, Electric Power Research Institute.

THE USE OF CHROMIUM IN STEELS FOR AEROSPACE, Rod Simenz, Lockheed-California Co.

USER'S VIEWS - OIL COUNTRY USAGE TRENDS IN CRITICAL MATERIALS FOR STEELS OF THE FUTURE - CHROMIUM, John W. Kochera, She11 Development Co. 
Impact of Developments in Manufacturing and Process Controls on Conservation and Recovery of Critical Materials

STAINLESS AND SPECIALTY STEELS AOD, EBR, LR, VAR, VIM, VOD, JameS T. Cordy, Universal Cyclops Specialty Steels Co.

P14

MINI MILLS-TECHNOLOGICAL INNOVATIONS AND FUTURE ALTERNATIVES, Peter H. Wright, Chaparral Steel Co.

P15

FUTURE RAW-MATERIAL REQUIREMENTS FOR STEEL PLANT REFRACTORIES, David H. Hubble and K. K. Kappmeyer, U.S. Steel Corp.

P16

RECYCLING-PRESENT AND FUTURE: "POTENTIAL FOR CONSERVATION" Herschel Cutler, Institute of Scrap Iron and Steel.

P17

Conservation and Substitution For Chromium in Stainless

Steels for Chemical Use and For Corrosion Resistant Applications

AN OVERVIEW OF THE POTENTIAL FOR CHROMIUM CONSERVATION IN STAINLESS STEELS FOR CORROSION APPLICATIONS, Gerald L. Houze Jr., Allegheny Ludlum Steel Corporation.

SUMMARY OF STUDIES OF METAL PROPERTIES COUNCIL ON CHROMIUM CONSERVATION IN STAINLESS STEELS FOR CORROSION APPLICATIONS, A. 0. Schaefer, Metal Properties Council.

CHROMIUM CONSERVATIONS IN STAINLESS STEELS: STATUS OF MPC ACTIVITY, Jim Heger, Consultant, Metal Properties Council.

CHROMIUM SUBSTITUTION PLANNING AT THE AMERICAN STERILIZER COMPANY, Roy S. Klein, The American Sterilizer Co.

ALTERNATES FOR STAINLESS STEELS IN THE CHEMICAL PROCESS INDUSTRIES, Edward A. Kachik, Materials Technology Institute of Chemical Processing Industries.

OPPORTUNITIES FOR CONSERVATION OF CHROMIUM IN CHEMICAL PROCESS EQUIPMENT, Robert A. Gaugh, ARMCO Inc.

APPROACHES TO CHROMIUM CONSERVATION IN MATERIALS FOR CHEMICAL PROCESSING INDUSTRIES, Aziz I. Ashpahani, Cabot Corporation.

POTENTIODYNAMIC CORROSION BEHAVIOR FOR SEVERAL FE-MN-AL AUSTENITIC STEELS, Rosie Wang and R. A. Rapp, Ohio State University. 
VOLUME II B: Proceedings of a Public Workshop; "Trends in Critical Materials Requirements for Steels of the Future; Conservation and Substitution Technology for Chromium".

Conservation and Substitution For Chromium in Stainless Steels and Alloys For Heat Resistant Application

OUTLOOK FOR CONSERVATION OF CHROMIUM IN SUPERALLOYS, John K. Tien, Juan M. Sanchez, and Robert N. Jarrett, Center for Strategic Materials, Columbia University.

DEVELOPMENT OF 9 CR-1 MO STEEL, Vinod K. Sikka, Oak Ridge Nationa 1 Laboratory.

SILICON-MOLYBDENIUM DUCTILE IRON FOR ELEVATED TEMPERATURE SERVICE TO CONSERVE CHROMIUM, Jan Janowak, Climax Molybdenum Co.

THE 1982 STATUS REPORT OF MN-AL-FE STEELS AS REPLACEMENT FOR STAINLESS IN HEAT RESISTING AND CRYOGENIC APPLICATIONS, Samir K. Banerji, Foote Minerals Co.

Conservation and Substitution For Chromium in Carburizing, Heat Treatable Steels and Bearing Steels

THE DEVELOPMENT OF NEW ALLOYS TO REPLACE CHROMIUM IN CARBURIZING STEELS FOR GEARS AND SHAFTS; Carl J. Keith and V. K. Sharma, International Harvester Co.

CHROMIUM-FREE STEELS FOR CARBURIZING, George T. Eldis, D. E. Diesburg, and H. N. Lander Climax Molybdenum Co.

RARE EARTH BORON STEEL (25-Mn-Ti-B) GEARS REPORT FROM NANCHANG GEAR PLANT, BEIJING, CHINA, Presented by Dale H. Breen and Allen G. Gray.

POTENTIAL FOR SELECTIVE HARDENING BY INDUCTION IN CHROMIUM-FREE STEELS, Peter A. Hassel1, Ajax Magnethermic Corp.

BEARING STEELS OF THE 52100 TYPE WITH REDUCED CHROMIUM, Chester F. Jatczak, The Timken Co.

Conservation and Substitution For Chromium in Structural Alloy, High Strength, and High Strength Low Alloy Steels

AN OVERVIEW OF CONSERVATION AND SUBSTITUTION FOR CHROMIUM IN STRUCTURAL ALLOY, HSLA AND ULTRA HIGH STRENGTH STEELS, Robert T. Ault, Republic Steel Corporation.

ALTERNATIVE COMPOSITIONS FOR FUTURE HSLA STEELS, Brian L. Jones, Niobium Products Co. 


\section{Potential For Advanced Technologies in Chromium Conservation-Coating Systems And Surface Modification Technology; Ceramics, Composites And Intermetallics}

OPPORTUNITIES FOR SURFACE MODIFICATION TECHNOLOGY IN CONSERVATION OF CHROMIUM, Peter G. Moore, Naval Research Laboratory.

SALT BATH TREATING AS AN ALTERNATIVE FOR CHROMIUM PLATING, William G. Wood, Kolene Co.

CLAD METALS: MATERIAL CONSERVATION THROUGH DESIGN FOR CORROSION CONTROL AND HIGH PERFORMANCE, James T. Skelly, Texas Instruments, Inc.

POTENTIAL FOR POLYMER CONCRETE TO CONSERVE ALLOYS IN ENGINEERING APPLICATIONS, Jack J. Fontana, Brookhaven National Laboratory.

ELECTROLESS NICKEL AS A SUBSTITUTE FOR CHROMIUM PLATING IN INDUSTRIAL APPLICATIONS, Ronald N. Duncan, Elnic Inc.

DEVELOPMENT OF DUCTILE POLYCRYSTALLINE NI ${ }_{3}$ AL FOR HIGH TEMPERATURE APPLICATIONS, C.T. Liu and C.C. Koch, Oak Ridge National Laboratory.

INJECTION MOLDING CERAMIC PARTS FOR HIGH TEMPERATURE APPLICATIONS, Beebhas C. Mutsuddy and Dinesh K. Shetty, Battelle-Columbus Laboratories.

Information Stockpile - Summary of Comments

DEVELOPING AN INFORMATION STOCKPILE TO AID IN SUBSTITUTION

PREPAREDNESS, Robert T. Nash, Vanderbilt University. 


\section{EXECUTIVE SUMMARY}

The present review of critical materials requirements in the American steel industry is particularly timely because of the severe depression being felt in the sale of steel, caused by the current world-wide recession, and compounded by increasingly strong competition from abroad. This competition is viewed as an unusually severe challenge because it is based on capital-intensive advanced processing technologies, which American companies now find difficult to finance. For the U.S. industry, the key to a strong competitive position is better performance, superior product quality, and reduced costs. These in turn will be achieved through technical developments in processing and in innovative materials. The nature and direction of the advances in these two technical areas will influence strongly the industry's future materials requirements.

Processing trends will affect demand for all raw materials, but differ in detail among the three major sectors of the industry: specialty producers, mini mills, and integrated mills. The specialty steel sector has stayed relatively competitive through technolgical leadership. The mini mill sector has remained relatively healthy through use of advanced technology, much of it developed abroad, and by careful limitation of product lines and proximity to materials and customers. Integrated mills have increased their use of advanced continuous casting technology to $22 \%$, but foreign competition is much farther along the road to optimal implementation of continuous production.

In addition to completion of the move to continuous casting, a move to fully automated, real-time controlled ladle metallurgy will increase productivity and quality control in the integrated sector. Moreover, the increasing emphasis on the production of "clean steels" 
has the potential to decrease our need for imported materials while at the same time increasing the performance of our steels and therefore our competitiveness in world markets. These "clean steels" depend on sophisticated processing to achieve desired properties rather than on large quantities of alloying elements. The broader application of near net shape and surface modification technologies is expected to have similar effects.

Some advanced processing technologies such as the argon oxygen decarburization process increase the relative attractiveness of South African ferrochrome over more expensive types from other parts of the world. The resulting increased dependence on South African ferrochrome will be modified, however, by lower overall demand due to a decreasing requirement for chromite refractories and a decreased need for chromium in a broad spectrum of advanced materials.

Use of recycled materials is one factor in the success of the mini mills. There is substantial room for increased use of recycled materials in integrated production.

Raw materials for which the American steel industry does not have North American supplies commercially available are chromium, manganese, columbium, and cobalt. These are therefore the materials for which alternatives are particularly important.

In the steel industry, cobalt is used primarily for tool steels, for which non-cobalt-containing alloys are commercially available. Substitutes for columbium and manganese have also been identified, although they are not so economical as the alloys containing columbium and manganese. Moreover, the quantities of manganese required are such that substitution of a substantial fraction would disrupt the markets for the alternatives. Because chromium is so inexpensive and provides a 
variety of special functions in steels, cost effective alternatives to chromium have not been proven for many of its uses. A number of opportunities exist, however.

Chromium is used primarily in two types of steels. The largest single use of chromium is in stainless steels, to which chromium imparts corrosion resistance, oxidation resistance, and stabilization of the austenitic structure. Chromium is used also in structural steels, to which chromium imparts strength, especially in high temperature applications, fatigue resistance, especially in ultrahigh strength s.teels, and hardenability.

Although no other element is known to produce corrosion resistance comparable to that imparted by chromium, the chromium content of the most widely used stainless steels, austenitic stainless steels, can be reduced without impairing corrosion resistance in many applications for which the traditional 18 percent is unnecessary. Use of duplex steels with large amounts of chromium may actually reduce chromium use by permitting substantially smaller amounts of these high strength steels to replace the traditional types. Near net shape and coating technologies can also reduce the amounts of chromium required.

For many specific appications of these materials, other materials without chromium are commercialy available or apppear feasible. For air oxidation at high temperature chromium may be replaceable by aluminum, although processing is extremely difficult. In structural applications, chromium-free grades are commercially available, and computerized models for new alloy design are currently available. Non steel alternatives such as titanium, tantalum, glass, and plastics also provide potential alternatives in some applications. 
Although a number of technical alternatives are either commercially available or are believed to offer real promise, several institutional barriers impede their exploitation. In some cases the current levels of imported constituents are no longer required because of changes in processing technology but continue to be used because specifications have not have not yet been modified. In other cases, elaborate qualification procedures discourage experimentation with alternatives. The utility of the chrome ore in the National Defense Stockpile is dropping rapidly as our ability to process this raw material is lost to less expensive foreign suppliers in South Africa. Finally, the realization of the promise of a number of the alternative technologies will require research and development to verify performance and to establish costeffective production. 


\section{INTRODUCTION}

In the present economic climate featuring weak markets, active foreign competition, and expensive capital, financial survival is the immediate concern of much of the U.S. steel industry; technical issues including critical materials needs seem less urgent. At the same time, competitive strength is closely correlated with the use of modern technology, to achieve better performance, superior product quality, and reduced cost. These are being achieved through technical developments in processing and new materials. The nature and direction of advances in these two technical areas will influence strongly the industry's future raw material requirements. This Summary Report identifies the opportunities in advanced processing and alternative materials that are likely to be the most important factors in the future of U.S. steel industry and for the raw materials required in the production of steel.

A wide range of materials is used in steelmaking because steels with a wide variety of properties and many engineering uses are demanded. Substantial quantities of manganese, chromium, molybdenum, nickel, tungsten, columbium, boron, silicon, vanadium, aluminum, and titanium are used in current steel technology for alloying. Tin and zinc are used as well for coating. These materials are "critical" in the sense that they are essential to the production of certain types of steel (using existing processes) and in the sense that changes in the availability of some would affect profoundly the cost structure and product mix of the steel industry and of the industries that use steel. The sudden necessity to use unfamiliar materials would inject uncertainty and jeopardize performance in affected industries and defense planning.

However, not all of these materials are "strategic" in the sense that supplies are highly uncertain. Molybdenum, boron, silicon, and 
vanadium are produced commercially in the United States although 40 percent of the vanadium used is imported. For aluminum there are commercial domestic bauxite sources as well as major commercial sources in Jamaica. Domestic titanium ores are utilized for titanium dioxide production.

The American Iron and Steel Institute (AISI) identifies the following alloying materials used for steel production as those on which the U.S. is most seriously import dependent: chromium, manganese, cobalt, nickel, and tungsten ${ }^{1}$ :

Chromium is used in structural and specialty steels where it imparts hardenability, corrosion resistance, oxidation resistance, and high temperature strength.

Manganese is used in the processing of all steels for deoxidation, desulfurization, or control of carbide and sulfide morphology. In the finished steel it provides toughness, strength hardenability, and hardness.

Cobalt is used primarily in tool steels and in some high strength steels; it contributes to high temperature strength and increases carbide tool life by acting as a binder.

Nickel increases hardenability and improves strength and toughness in specialty steels; nickel establishes the austenitic structure in high chrome steels; it is added with chromium to increase corrosion or oxidation resistance and high temperature strength.

Tungsten is used in tool steels to stabilize carbides; it develops high temperature hardness, contributes to creep strength, and increases hardenability.

In addition to the five elements listed above, columbium is 100 percent imported, primarily as ferrocolumbium for steel production. It is 
used in high strength low alloy steels as a strengthening agent, in austenitic stainless steels as a carbide stabilizer and in carbon steels.

For these elements the probability for total supply disruption varies significantly. Nickel and tungsten are now obtained from large domestic and Canadian sources. Two thirds of U.S. columbium demand is currently supplied by Brazil, which has sources of high grade low cost ore capable of supplying 70 percent or more of world demand through the year 2000. There are also domestic sources now inactive that could be reopened in the event of a price rise. About 90 percent of U.S. cobalt demand is now supplied by imports mainly from Zaire and Zambia. For cobalt two formerly commercial domestic sources are available that could be developed in an emergency. Manganese is almost totally imported; manganese sources are distributed world-wide including potentially significant reserves in Mexico and large commercially developed high grade sources in Africa, Australia, Brazil, and India. Finally, chromium is not available in the western hemisphere, and a centralization of supply in southern Africa is projected after the turn of the century ${ }^{2}$. In summary, current sources for columbium, cobalt, chromium, and manganese are all foreign, and for the first three of these, the sources are highly localized.

The American Iron and Steel Institute classifies steels into four groups according to major alloying element content as follows:

- Carbon Steels: Properties for these steels are determined primarily by carbon content; these steels always contain manganese (up to 1.65 percent) and usually minor amounts of sulfur, silicon, and phosphorus. These are high volume 
steels with diverse uses in plate, castings, tubing, wire products, structural shapes, strip, and rails.

- Alloy Steels: Alloy steels are those that contain more than 1.65 percent manganese, 0.6 percent silicon, 0.6 percent copper or other specified elements. An important subgroup, high strength low alloy (HSLA) steels, contain minor but important amounts of one or more of the following elements: manganese, silicon, copper, vanadium, zirconium, nickel, columbium, titanium, and chromium. Alloy steels are used primarily for structural applications.

o Stainless and Heat Resisting Steels: These steels contain chromium and often nickel in concentrations as high as 30 percent; high volume grades contain 18 percent chromium, and 8 percent nickel. Stainless steels are used for special or structural applications requiring corrosion resistance, oxidation resistance, and/or high temperature strength. Large amounts are also used for decorative and functional applications such as automobile wheel covers and trim, kitchen sinks and flatware.

- Tool Steels: These steels contain substantial amounts of cobalt, tungsten, molybdenum, and some chromium. They are used for operations requiring hardness and wear resistance.

As noted above, the development of technology in two particular areas, processing and innovative materials, can greatly affect future raw materials requirements for steel production. Technological changes in processing that will affect materials requirements are discussed in the next section. Potential alternative materials are reviewed following 
that. Resulting institutional questions are summarized next. Finally, the relationship between materials requirements and industrial productivity is reviewed.

Cobalt substitution and conservation was addressed in a 1981 Workshop at NBS on aerospace industry materials. In order to obtain recent information on important developments and trends in chromium conservation since the mid 1970 s, when its use was reviewed comprehensively ${ }^{3}$, the National Bureau of Standards in concert with the Bureau of Mines and the Army Research Office, organized a public workshop at Vanderbilt University in October 1982. This workshop, "Trends in Critical Materials Requirements for Steels of the Future; Conservation and Substitution Technology for Chromium," provided important verification of many technical trends already evident at the time of the National Materials Advisory Board study. 


\section{Current Economic Status of the Industry}

Rapid changes that are now taking place in steel technology improve both performance and yields. This innovation will therefore affect profoundly the requirements for all raw materials. However, an analysis of the technological opportunities presented to the steel industry must recognize that the current financial climate of the industry is extremely serious $^{4-7}$. The survival of large segments of the U.S. steel industry is felt to be at stake. The implementation of known technological opportunities and the definition of new technical approaches that will improve future productivity are recognized as essential to the future of the industry, but are now seen as hostage to the introduction of new capital in the integrated steel industry.

Current slackness in demand for steel is a worldwide phenomenon. It derives in part from the general recession, but is more ominous than the status of other sectors because of overcapacity for steel production in the world as a whole. The resulting concern in the U.S. steel industry for its markets is compounded by the increasing pace of technological developments in recent years ${ }^{8}$ and the current inability of the U.S. steel industry to finance the capital investment required to exploit these developments threatens to further weaken the U.S. international competitive position.

A review of materials requirements of the industry and associated technical opportunities must take into account the overwhelming importance to the industry of this question of survival. The current competitive 
position of the industry and the world economic climate severely limit the nature and timing of action that can be beneficial. However, this review of the technological trends of the industry as it faces the necessity for major investments in capital equipment is particularly timely precisely because of the choices in technology that are now available, and that must be faced and anticipated as the industry girds itself for the future.

\section{Technical Status of the Three Major Sectors}

The steel industry can be divided into three major sectors for the purposes of this analysis: the large integrated mills, the mini mills, and the specialty steel sector.

The integrated mills produce the bulk of the steels made in the U.S. Carbon and low alloy steels, which constitute the largest volume of steel production, are made primarily in plants that individually produce in excess of two million tons annually. This heavily capitalized sector of the industry faces the greatest challenge in modernization in order to improve its international competitive position. This challenge is exacerbated by a general shift in the market toward alloy steels.

As already noted, a primary concern with respect to the integrated mill sector is its current inability to finance the development and acquisition of efficient production technology for traditional steels and for advanced low alloy steels $s^{5}$. In planning for the modernization of production technology through capital investment, the industry needs to anticipate changes in demand for alloy steels. Of particular importance in anticipating future markets is recently increased understanding 
and control of processing technology, which enables producers to achieve properties through specialized processing rather than through the addition of relatively large quantities of alloying elements. For example, the growth in demand for HSLA steels is likely to continue as demand for these steels spreads into areas such as automobiles ${ }^{9}$.

The mini mill sector concentrates on a small range of products from among carbon and low alloy steels which are made in mills individually producing less than one million tons annually. By thus restricting the product range and the relatively low level of capitalization required, and through low transportation costs made possible by utilization of locally generated scrap and marketing in the vicinity of the plant, the mini mill sector has remained profitable even through the current recession ${ }^{10}$. Although mini mills have achieved success by concentrating on relatively high volume, low cost steels, the success of these mills is traceable in part also to the introduction of innovative processing technology. In this case however, in contrast to the specialty steel industry, the technology has not been developed by the producers themselves. Much that is used in fact comes from abroad. The importance of potential foreign competition for markets in this sector is mitigated by the dominance of transportation costs in the relatively low cost product. The manufacturing technology of the mini mills is continuing to develop rapidly 10 .

The specialty steel industry, which produces not only stainless steels and tool steels but also superalloys, has remained relatively profitable through leadership in innovation that makes it technically competitive worldwide. This sector is of particular importance in a review of imported materials requirements of the industry because the 
production of stainless steel alone consumes more than half of all of the chromium used in the U.S. economy.

The technical leadership of the specialty steel industry has been achieved and maintained through the development and introduction into practice of a series of processing technology breakthroughs, which in turn have stimulated the development of a wide range of steels serving other high technology industries ${ }^{6}$.

Thus, change in technology is central to the competitive status of all three steel industry sectors. The changes differ in the three sectors, but in no case are they due to uncertainty over raw materials supplies. However, investment choices to ensure that the steel industry be competitive world-wide must be made during a period when supply uncertainties need to be anticipated.

\section{Technical Developments in Processing}

As already noted, innovation in processing will affect strongly both the performance of steel and the yields in its production. This innovation will therefore affect future raw material requirements in the industry, especially the requirements for non-ferrous additives.

\section{Continuous Casting}

Continuous casting has been introduced in all major sectors of the steel industry. It offers improved quality over previous processing technology: better homogeneity, beneficial inclusion morphology and distribution, and better surface quality. At the same time it offers substantial cost advantages through reduced cropping, energy consumption ${ }^{11}$, 
and for some production the elimination of the blooming mill. Yield improvement varies with steel grade from 10 to 20 percent $^{11-13}$.

Domestic production by continuous casting has increased as a proportion of total production, from 9 percent in 1975 to 22 percent in $1981^{11}$. Most of the bar and rod production is continuous cast today along with a substantial fraction of the "flat" production" ${ }^{5,13}$. Large structural pieces are not continuously cast. The use of continuous casting is growing ${ }^{14}$ and is expected to penetrate 45 percent of the industry by 1990. However, in 1981 Japan and Europe already produced 71 and 45 percent of their steels, respectively, by continuous casting. The severe challenge presented by foreign steel is ascribed in part to their advances in this area. The success of the mini mill sector of the U.S. production is due in part to the fact that it uses continuous casting exclusively, thereby achieving an increase in yield over ingot practice of 18 percent $^{10}$.

The use of continuous casting technology by the specialty steel sector is considered to be fully competitive with the practices of foreign producers ${ }^{6}$. Use of this technology has been credited with an improvement for chromium yield in stainless steel of 10 to 15 percent when used in conjunction with the argon-oxygen decarburization (AOD) process $^{15-16}$. Both the improved performance of the resulting product and the improvements in yield lower requirements for raw materials.

\section{Primary Melting and Refining Processes}

Specific properties in steels have traditionally been established by the incorporation of alloying elements. Common alloys contain such elements at a level of $2 \%$ to $4 \%$. The most widely used stainless steels 
contain about $18 \%$ chromium. In order to achieve unusual properties, the metallurgist may add even larger quantities of chromium. For example, special alloys such as some special welding electrodes contain $30 \%$ chromium and $9 \%$ nickel.

Recent developments in duplex processing, separate electric furnace melting and ladle refining in particular AOD, have significantly improved the manufacture of stainless steel. It is difficult to decarburize by oxidation without also oxidizing the chromium. The traditional way to handle this challenge is to decarburize low chromium melts and then bring the chromium composition up to its final value by the addition of expensive low-carbon ferrochrome. In addition, decarburization must be performed at high temperatures in order to minimize but not eliminate substantial losses of chromium due to oxidation. Modern refining options such as $A O D$ lower the carbon monoxide partial pressure by blowing varying proportions of argon-oxygen mixtures. The throughput of argon removes the carbon monoxide reaction product and permits continued oxidation of the carbon at lower tempratures in the presence of the final amount of chromium. The economic benefits from duplexing processes include use of lower cost raw materials (e.g., high carbon ferrochromium), improved chromium recovery, and lower processing costs through lower processing temperatures.

Utilization of vacuum refining exploits the pressure dependence of the carbon oxidation reaction and thus also permits lower decarburization temperatures. The result is simultaneous lower carbon content, and reduction of chromium 1oss. Conventional electric furnace melting and oxygen blowing results in chromium losses of between 10 and 15 percent. Vacuum-oxygen decarburization (VOD) reduces the chromium loss to 6 percent. 
Furthermore, the use of either VOD or AOD improves the final properties of the steels due to their lower gas and impurity contents.

The trend in the production of low alloy construction steels containing chromium is also toward duplex vacuum refining systems. Chromium losses of 7 to 10 percent encountered in conventional processing can be reduced to less than 4 percent.

Recently developed duplex processes, are much more cost effective than previous processes. New duplex processes allow large-scale removal of impurities and the subsequent, precise addition of other costly elements rather than the addition of large quantities of costly alloying elements to "tie up" high levels of impurities. Process advances have also helped the development of new alloys such as HSLA steels for the transportation industry. The need to lighten vehicles in order to save energy has led to a strong demand for weight reduction and a corrolary strong demand for these higher quality and higher strength-to-weight steels. Concern for the high consumption of energy in processing has added a strong desire to eliminate the energy-expensive elaborate heat treatment in fabrication. HSLA steels $\mathrm{s}^{14}$ and other clean steels ${ }^{12}$ successfully provide the needed increased strength without such heat treatment.

Thus sophisticated processing is being used to produce cost competitive steels that do not require large amounts of alloying elements and elaborate heat treatment. The success of this approach is based on achieving an understanding of the specific influence of the various fabrication process variables on steel microstructures and a detailed prediction of the properties of steels based upon the microstructures thus produced. This approach has resulted in the design of new steels 
with properties superior to those traditionally achieved through the use of large alloy additions ${ }^{17}$.

In duplex steelmaking the achievement of microstructure in high temperature alloys requires the introduction of special melting and remelting techniques. Among these are vacuum induction melting (VIM) and secondary remelting operations such as vacuum arc remelting (VAR) and electroslag remelting (ESR). The vacuum techniques remove trace elements that have a high vapor pressure while the refining processes in, for example, ESR reduce sulfur to very low levels. Fine grain structure and segregate spacing, which are necessary to the achievement of the desired high strength and workability, are also achieved in these processes by use of high cooling rates during solidification. While these processes reduce impurities to very low levels, they permit maximum alloy conservation and narrow ranges of composition variations, hence optimum properties.

The result of this succession of sophisticated melting and refining steps is the production of steels with reduced losses of critical alloying elements, and steels with competitive or superior properties. These properties are achieved, moreover, with a sufficiently low alloy content to be cost competitive with traditional stee $1 s^{9,11}$.

\section{Real-Time Control}

Part of the challenge faced by the U.S. steel industry is the desire by its customers for improved quality control. Materials problems in the construction of major bridges are an example of this challenge ${ }^{18}$. A recent study by the National Bureau of Standards and Battelle Columbus on the national costs of fracture ${ }^{19}$ identifies the economic benefits in 
reducing the range of property variability in structural materials through processing improvements and tighter quality control. This would result in more efficient use of construction materials and therefore a saving in raw materials, including strategic supplies. This study also notes the importance of non-destructive evaluation and real-time control during processing for achieving the needed improvement in variability.

Continuous casting and ladle metallurgy offer the chance to achieve the improved quality desired ${ }^{11}$. However, in order to realize this improvement in fact, closer control of processing will also be necessary, especially for casting, rolling, and annealing 9 . With real-time control, the more uniform chemical composition, hardenability, toughness, and surface quality that must be achieved for steels in general, and for high strength steels in particular, can be produced. Although the acceptable "window" in properties is constantly being made smaller, productivity can actually be improved simultaneously through this control ${ }^{11}$. Increased productivity will follow not only from the improved and more consistent properties but also from higher yields through improved dimensional control and minimization of the remaking of heats ${ }^{15}$, and from more efficient utilization of the energy required in heating furnaces 8,14 . Requirements for all raw materials including chromium will be reduced correspondingly.

The use of dynamic control has already been widely adopted in the basic-oxygen steelmaking technology. Here it has lowered oxidation losses. The computer control of alloy additions is also receiving increased emphasis 5 .

The American Iron and Steel Institute and its member companies have recognized the importance of real-time control in achieving increased 
productivity. They have noted that the development of sensors was essential to achieving such active control. Four groups of sensors were identified to be of primary importance: (1) automatic detection of porosity; (2) on-1ine inspection of defects; (3) rapid in-process chemical analysis of the molten metal, and (4) rapid measurement of the temperature distribution within a solid or solidifying body of hot stee 1. These sensor needs were described to interested scientists and engineers in a Workshop held at the National Bureau of Standards in July, $1982^{20}$. Programs to address these needs are now being developed by the American Iron and Steel Institute.

\section{Near Net Shape Technology}

The production of parts by powder metallurgy minimizes material and energy utilization ${ }^{6}$. Moreover, by use of powder formed by rapid solidification, alloys with special microstructures and therefore with properties not possible by means of conventional metallurgical techniques can be made through powder metallurgy.

These microstructures and their concomitant lower segregation can result in improvements in fracture toughness, corrosion, wear and oxidation resistance. These properties are of particular interest for alloy steels, tool steels, and stainless steels ${ }^{14}$, high alloy bearings, tools and dies, and jet engine discs ${ }^{2}$. The resulting alloys have improved hot workability and have led to new concepts in alloy design ${ }^{15}$. Powder metallurgy has received considerable attention both in industrial research for application in special areas and in government programs supporting long range basic investigations. 
The results of these efforts to date have been alloys that have already reduced the need for chromium somewhat ${ }^{2,15}$; further possibilities are foreseen both for the reduction of the fraction of chromium contained and for the reduction of scrap in fabrication. Other powder metallurgy techniques are also affecting the balance among various fabrication technologies. For example, some sintered iron powder parts may replace forged steel in automobiles ${ }^{9}$.

\section{Surface Modification}

Three of the principal uses for chromium in steels are resistance to corrosion, oxidation, and wear. Because these characteristics depend on surface related properties, surface modification may serve well as a chromium conservation measure in areas where these properties are important. Moreover, surface modification can offer distinct advantages. One is the growing ability to treat surfaces of objects in order to give them special microstructures not achievable in the bulk at all or perhaps only by the sacrifice of other desirable properties. Surface modification thus is not to be viewed just as a substitute but rather as a processing option. Among the performance advantages are the extension of the life of tools and other parts ${ }^{2}$. Particularly promising options include: cladding and lining, weld overlaying and hardfacing, thermal spray coating, surface impregnation ${ }^{21-22}$ such as ion implantation, directed high energy (laser and electron) beam processing ${ }^{23}$, and chemical and physical vapor deposition.

From the perspective of the steel industry as a whole, surface modification plays two distinct roles. First, it may be part of the processing in the steel mill and therefore is to be examined in the 
context of changing processing technology in the steel industry. Second, surfaces may also be treated "down stream" by industries that purchase steel from the steel industry and utilize it in products. The stee 1 industry has an interest in such technology to the extent that it modifies anticipated demand for steel of certain types or to the extent that such later processing will affect requirements for the steel produced, such as type of surface finish.

Improved surface quality can result from bottom forming of ingots ${ }^{13}$. Coatings on the steel produced by the steel industry are also expected to play a more visible role in product demand. For example, the use of precoated and galvanized steel will affect demand for bare hot and cold rolled stee ${ }^{14}$. Other special products within the steel industry that are attracting attention are zinc-aluminum coated sheet steel and nickel-zinc electroplated steel strip ${ }^{14}$. Since high strength steels are as susceptible to corrosion as are other steels, but are more vulnerable because of their reduced gage, coatings for these steels are particularly important. For steels in general, not only is the performance of the material in the final product a factor, but improved corrosion protection at down stream manufacturing facilities has been identified as an area of concern ${ }^{5}$.

"Down stream" surface modification is growing in importance as the range of alternatives and the special properties that can be achieved advance rapidly. Among these areas are the electroless nickel process ${ }^{24}$, cladding ${ }^{15,25}$, chromizing, and nitriding ${ }^{11,26}$. cladding could affect chromium utilization either in the form of stainless cladding on base steels, which could reduce but not eliminate the demand for stainless steels and the chromium that they contain, or through tantalum, 
zirconium $^{27}$, or titanium cladding, which would eliminate the use of chromium al together.

\section{Steel Plant Refractories}

Significant shifts have been noted in refractory usage in the steel industry. These trends are expected to continue in the future and are due to changes in steel processing, improved steel quality requirements and the use of more severe environments in the production of steel. The total refractory usage in steel has declined from 65 to 70 percent of the total refractory consumption in the U.S. in the 1960 s and 1970 s to approximately 50 to 55 percent today ${ }^{28}$. In general, lower refractory consumption is attributed to improved service life and the use of sophisticated processing of raw materials. A brief look at refractory usage in modern ironmaking, steelmaking, refining, and casting reflects the changing demand for refractories both domestic and imported.

The larger modern blast furnaces with higher operating temperatures and better process control require more dependable, longer life, refractories containing high-alumina (for which we are import dependent), silicon carbide, and graphite materials. Reduction in use of refractories in the face of the more severe environments present in the modern blast furnaces is traceable to a number of factors. Use of furnace cooling has grown. Tighter combustion and slag composition controls, gas cleaning, and the avoidance of other contamination have played a role as well.

Open hearth furnaces formerly required a continuing supply of chromite refractories for use in an environment that made for a severely limited lifetime. Recent emphasis on basic-oxygen steelmaking 
has reduced both the overall refractory consumption and changed the mix of the refractories used. Again, better refractories, slag-composition control by dolomite, and improved process control have increased refractory lifetime. Furthermore, the basic-oxygen steelmaking refractories are based on periclase (domestically produced from brine or seawater) with carbon from pitch or amorphous sources. These changes have reduced the steel industry requirements for chrome-ore refractories.

In electric furnace steelmaking, the trends are again toward extensive use of water-cooled panels, and the remaining refractories are based on periclase with graphite and carbon. Usage of refractories in the AOD furnaces is also declining due to improved materials and blowing practices. Both dolomite (with excellent quality deposits in the U.S) and periclase-chrome are used. In the event of a chromite shortage, dolomite could become the exclusive refractory used in $A O D$.

Improved refractories are also used in ladles, tundish and flow control systems. Fireclay and fireclay-graphite in ladles are being replaced by high-alumina or basic (dolomite, periclase-chrome, periclasecarbon) refractories in order to improve steel cleanliness. This bauxite is imported ${ }^{29}$ because domestic bauxite is unsatisfactory for the production of the high purity material required in these steels $\mathrm{s}^{30}$. Tundish and tundish flow control systems in continuous casting use high-alumina liners and periclase consumable liners. The important trend here is to control formation of $\mathrm{Al}_{2} \mathrm{O}_{3}$ inclusions, by reduction of silica, which can plug passages as well as adversely affect properties. 
Import Implications of Advanced Technical Developments

The increased performance and yields common to the technologies described above will tend to lower dependence on imports generally. One concrete example of the magnitude of the changes that can be expected is the drop in the fraction of refractories used in the United States that is required by the steel industry. This drop of up to $20 \%$ is a measure of the suddenness with which such technological changes can occur when economically attractive technical opportunities appear.

Countering this trend, however, is a trend toward alloy steels. Another rapid change in import demand, but in the opposite direction, is that for South African high-carbon ferrochromium. The argon-oxygen decarburization process has increased the ability of steel makers to use this high-carbon ferrochromium. Simultaneously, the increase in transportation and energy refining costs have made the processing of ferrochromium in southern Africa more cost effective ${ }^{2,31}$. The result has been an increase in the southern Africa's share of the world market in ferrochromium from $15 \%$ to $37 \%$ between 1970 and $1979^{2}$. Although this dependence on a localized ferrochromium source is not expected to continue to increase further in the near future ${ }^{2}$, the prognosis over a period of 25 to 50 years is that the entire world will be dependent for its chromium entirely on southern Africa ${ }^{32}$.

The final balance between the decreased dependence by the steel industry on imported chromium generally, and the increased dependence on southern Africa specifically, is not quantitatively clear at this point. What is clear is that an increase in the availability of technical options will necessarily become more important as the dominance of a single supply region in the ferrochromium market increases. 
The use of recycling in the steel industry varies widely from sector to sector. Mini mills use scrap exclusively as their source of starting material ${ }^{10}$. However, the fraction of raw materials requirements supplied by scrap for the integrated mills in 1981 was substantially less than half, or 48 million tons ${ }^{12}$. Since plants both in the U.S. and in West Germany have operated on charges made up completely of scrap, utilization of scrap in this country could double, in principle. Increased use will be facilitated by increased capability for electric furnace melting.

The extent of the use of scrap depends on action at two distinct points in the materials cycle. The first is the generation of "prompt" scrap in the production process, either in the "home" plant or elsewhere. The second is the return of "obsolete" scrap to the producer after use by the consumer.

The extent of recycling of "home" scrap can be completely an internal matter in an individual company. The economic utilization of this "home" scrap is frequently facilitated by the establishment of a system for segregation of the scrap close to its generation. By such segregation, reprocessing costs may be made much lower than those required if scrap from a number of sources either "prompt" or "obsolete" is mixed. There is therefore typically an "induction period" for the establishment of more effective utilization of home scrap. However, this system is at the discretion of the local plant management.

Current utilization of home scrap by the steel industry varies strongly according to the type of steel produced. There are two major factors in this variation, the amount of scrap generated in the process, 
and the requirements imposed by purchasers, who may demand that only virgin material be used. Recycling of home stainless steel scrap recovers only nine percent of total demand ${ }^{2}$, largely because relatively little scrap is generated in production. Recycling of home scrap in the production of aircraft engines recovers only 60 percent of the much larger fraction of superalloy scrap produced. As the yield of processing technologies increases, the amount of scrap available will fall off. For example, the improvements that are foreseen in the basic-oxygen furnace yields suggest that this technology will no longer be self sufficient in the production of home $\operatorname{scrap}^{12}$ and will be able to utilize prompt scrap from other sources.

The areas that have been identified as primary candidates for increased attention in recycling are fume, dust, and slag generation in addition to improved segregation ${ }^{5}$. The Bureau of Mines is developing technology to facilitate this recovery ${ }^{2}$.

The challenge in increasing the recycling of obsolete scrap is perhaps greater. A major hurdle in meeting this challenge is the establishment of a collection mechanism ${ }^{12}$. Another hurdle is the assignment of the substantial risk involved. The extent of recycling of both types has proved to be highly sensitive to the price of competing raw materials. 


\section{SUBSTITUTION}

This section addresses substitution as a means of conserving critical materials used in steel making. As noted above U.S. supplies of chromium, manganese, cobalt, and columbium are of major importance to the steel industry and are not commercially available from domestic sources.

For columbium, there are already alternatives 33 , including vanadium and molybdenum for high strength low alloy steels, and titanium and tantalum in stainless steel. However, some of these may involve a cost or performance penalty ${ }^{34}$.

Cobalt use in steels is primarily in tool steels and represents less than 10 percent of U.S. cobalt consumption. Two cobalt-free tool steels are commercially available. These are based on a powder process involving hot isostatic pressing ${ }^{35}$. This and other substitution options for cobalt were reviewed in a public workshop on aerospace materials ${ }^{36}$.

For manganese in steel, a number of technically feasible alternatives are known including nickel, molybdenum, and chromium. However, the very large amounts of material required to substitute for the 15 lbs of manganese required per ton of raw steel would disrupt the supply and delivery patterns of alternative alloying elements 37 .

Chromium use in stee 1 represents over 60 percent of U.S. demand for chromium. Within the industry, use is concentrated in alloy and stainless steels. Stainless and alloys steels account for about 1 and 10 percent, respectively, of total U.S. steel production, and yet these sectors alone consume 250,000 to 300,000 short tons of chromium per year. Because of 
its availability and low cost, research in chromium alternatives has not been pursued as thoroughly as for other alloying elements. However, a number of substitutes exist. This section reviews alternatives to chromium in steel, both available technologies and opportunities for new alternatives.

\section{Chromium Functions in Stee}

Chromium is used in stainless steels to impart corrosion resistance, oxidation resistance and to contribute to stabilization of austenite ${ }^{32}$. Chromium is required also for strength in structural steels, especially in high temperature applications; for high fatigue resistance in ultrahigh strength steels and for hardenability ${ }^{38}$. Chromium provides these properties inexpensively. Based on a long history of experimentation and evaluation chromium is therefore frequently the cost effective choice where any of these properties or a combination of them are required. However, for many applications other materials without chromium are either commercially available or appear feasible. For corrosion resistance, no element is known to be comparable to chromium ${ }^{32}$. However, chromium content in austenitic stainless steels can be reduced below the traditional 18 percent without impairing corrosion resistance in many applications.

\section{Substitution Options for Chromium in Corrosion and Oxidation}

\section{Resistant Stainless Steels}

Stainless steels for corrosion and oxidation resistance represent the largest single use of chromium, about 50 percent of U.S. demand for chromium and 70 percent of the chromium used in steel. One stainless 
stee 1 grade alone, type 304 , accounts for approximately 40 percent of total U.S. chromium consumption. Important uses of stainless steels are in the automotive (exhaust systems) and aircraft (ducting and tubing) industries. Stainless steels are also used throughout the construction, mining, and manufacturing sectors; major critical uses are in equipment for chemical processing, for oil exploration and drilling, and for electric power (coal and nuclear) generation. For oil country tubular goods which are used in high pressure, high temperature environments including exposure to sulphur, the use of chromium steels is increasing ${ }^{39}$. Although austenitic stainless steels contain 18 percent or more chromium, for corrosion resistance, passivity is achieved with 12 percent chromium and for most applications this amount will provide adequate corrosion resistance. Chemical industry applications may be exceptions ${ }^{32}$. The function of chromium in these steels as an austenite stabilizer can be performed as well by manganese so that in an emergency the chromium content of replacement steels could be reduced to 12 percent or lower. Such changes demand careful evaluation of the service requirements for the particular applications ${ }^{40}$. For example, austenitic steels with 14 percent as opposed to the traditional 18 percent chromium have oxidation resistance and adequate strength for $1400^{\circ} \mathrm{F}$ service ${ }^{41}$. A $9 \mathrm{Cr}-1$ Mo steel modified by small additions of $\mathrm{Nb}$ and $V$ is being tested as a replacement for $18 \mathrm{Cr}$ steels in steam power plant heat exchangers $21,42-43$. New higher strength duplex stainless steels and higher corrosion resistance (superferritic) steels can lower total chromium demand by requiring 50 percent reduced cross-section sizes although their chromium levels are higher ${ }^{40}$.

Replacement of chromium in stainless steel with aluminum and/or silicon is considered feasible in some oxidation resistant applications 
in absence of such corrosive compounds as $\mathrm{H}_{2} \mathrm{~S}^{26}$. Sometimes development of these new alloys is facilitated by development of new technologies such as rapid solidification processing (RSP) ${ }^{44}$. An example of this is a series of new $\mathrm{Fe}_{3} \mathrm{Al}$ plus dispersoid rapidly solidified alloys which have significantly improved cyclic oxidation resistance at $1100{ }^{\circ} \mathrm{C}$ compared with AISI 347 stainless steel and Haynes 188 alloy ${ }^{45}$. In another project aluminum steels (Fe-8Al-6Mo) are being developed which have demonstrated high temperature air oxidation resistance superior to that of type 304 stainless ${ }^{32}$. The cost of these alternative alloys however is likely to remain higher than the cost of stainless steel.

Some research has been undertaken on the intermetallic nickel aluminides as possible substitutes for austenitic high chromium steels in structural applications for elevated temperature, corrosive/oxidizing environments. These materials are currently not promising because of great difficulty in processing although progress has been reported in reducing the inherent brittleness of $\mathrm{Ni}_{3} \mathrm{Al}$ by microadditions of boron ${ }^{46}$. Need for further work on the low ductility of the intermetallics would be required in order to utilize their high temperature strength and chemical stability for chromium conserving applications.

Silicon added to iron or nickel also imparts excellent resistance to aqueous corrosion; the alloys are brittle however and commercially available only as casting. Exploitation of silicon alloys as a more general corrosion resistant substitute requires research to improve their mechanical properties $21,27$.

Development of new alloys without chromium is also underway: Iron-manganese-aluminum alloys are being developed to substitute for austenitic $\mathrm{Ni}-\mathrm{Cr}$ stainless grades in heat resistant applications at moderate temperatures and corrosion resistant applications in some 
environments $^{47}$. Although they are brittle, they have already been used successfully in furnace and ocean environment ${ }^{48}$. Nickel-copper and nickel-molybdenum alloys may also be used with some sacrifice of mechanical properties and corrosion resistance ${ }^{21}$. Silicon-molybdenum ductile iron has performed more effectively than high chromium steels in high temperature corrosive-erosive environments such as furnace grates and exhaust manifolds ${ }^{49}$.

Other alternatives to stainless steels in some corrosive environments are nickel, titanium, tantalum, ceramics and glass, and electroless nickel coatings. These are used now wherever they are economically attractive. Plastics and composites (e.g., fiber reinforced plastics) may possibly provide options to replace some stainless steel in corrosion resistant chemical processing equipment. The elimination of problems inhibiting wider use of plastics and composites is seen as one fruitful research area $^{27}$.

As previously noted, cladding and coating are important options for reduction of chromium use where its primary function is to provide surface protection from corrosion, oxidation, and/or wear 23,40 . The technology for cladding stainless steel is well established ${ }^{25}$, and since it has been demonstrated to reduce chromium requirements by 10 to 20 percent in currently economical applications it is an important conservation option for chromium. A substantial fraction of the stainless steel plate market (up to 200,000 tons), could be replaced by clad plate, saving the order of 30,000 tons of chromium per year ${ }^{3}$.

Other successful examples of this approach that could reduce chromium demand and in some cases improve corrosion, wear and fatigue performance are electroless nicke ${ }^{24}$ and nitriding ${ }^{26}$. They are widely 
used now where cost effective and could be used more widely for wear and corrosion protection if chromium were unavailable.

Electrodeposition can be adapted to surface alloy coatings. It allows application of relatively large amounts of material to the surface and can be accomplished at room temperatures without affecting previous heat treatments of the substrate. An important variant of electrodeposition, pulsed electrodeposition uses a pulsed dc current typically a square wave form and produces dense, unusually fine-grained or amorphous deposits of high purity.

Alloying elements may be diffused into the metal by applying a powder to the surface at elevated temperatures. For example, it is estimated that "chromized steel sheet", 0.002 " thick 25 percent chromium, diffusion bonded coating on low carbon sheet steel may be used as a low chromium alternative to ferritic stainless steel in special applications.

Ion implantation, a relatively new technique for surface treatment of metals, is a low temperature process that is easily controlled through electrical signals and is applicable to all elements. With ion implantation new metallurgical phases can be produced, including amorphous or glassy phases. It is now limited to applications where thin coatings are acceptable.

The latter two approaches may be used separately or in combination with surface melting, usually by laser or high energy electron beams to produce new alloys or to reduce concentration gradients near the surface 23 .

For special applications such as power turbines requiring high temperature strength, erosion and corrosion resistance, and machine tools requiring hardness and wear resistance, silicon based ceramics are potential alternatives to chromium containing steels and superalloys. 
The key problems are brittleness and fracture susceptibility; these may be solved by sophisticated design combined with successful research leading to microstructure/processing advances.

\section{Substitution Options for Chromium in Structural Alloy Steels}

Chromium is also used extensively as an alloying element to provide hardenability in a wide variety of steel grades. Altogether this use accounts for about 20 percent of U.S. chromium consumption ${ }^{3,50-51}$. Other alloying elements such as manganese and molybdenum are even more effective hardenability agents, and in many instances appropriate commercial alternatives are already well developed ${ }^{10,52}$. For many heat treatable steel applications, chromium free or low chromium alloys are commercially available. Other potential replacements are in development. Computerized models are being used to identify optimum alloy compositions for specific applications where individual alloy element composition is guided by cost $38,50,52$.

Carburizing steels for high temperature applications requiring case hardness and toughness may contain up to 5 percent chromium. However, the precise role chromium plays is not known and chromium free alternatives have not been identified. Based on successful development of alternatives for lower temperature service, prospects for developing chromium free carburizing steels are very promising ${ }^{52}$.

For high carbon steels (AISI 52100) used for ball bearings, alternatives have been developed with chromium content reduced from 1.45 percent to 0.5 percent. These have received wide customer acceptance in bearing applications 41 . 
Industrial research and development efforts have led to modified "commercial bar" alloys with no chromium and with suitable heat treatment characteristics and mechanical properties ${ }^{38}$. Chromium-free steels are also commercially available in structural plate and abrasion resistant plate categories. In addition, computer models for predicting hardenability, properties, and heat treatment requirements are now available to facilitate development of new alloys such as weathering steels. These are being applied, for example, in a Bureau of Mines supported project to develop two chromium-free steels as cost effective replacements for two AISI-SAE standard alloy series ( 8600 and 4100 ). These alloys are construction grades containing 0.8 to 1.1 percent and 0.4 to 0.6 percent chromium, respectively, and account for approximately 10 percent of the total U.S. chromium consumption 50-51.

HSLA steels have been used to meet a combination of strength, toughness, and weldability requirements for pipeline service ${ }^{43}$ and for fuel saving weight reductions in the transportation industry. The strength of these steels does not depend on traditional hardenability approaches and the majority do not contain chromium ${ }^{17}$. They constitute a new class of steels with good strength, toughness, and formability. This has been achieved as a result of applying advances in understanding of processing/microstructure/property relationships; i.e., by using micro additions (less than 0.1 percent of key alloying elements) and controlled thermomechanical treatments ${ }^{17}$. The use of these steels may be expanded to supplant chromium-containing heat treatable steels 53 .

For most structural steel grades chromium-free substitutes are available or substitution technology appears adequate. Indeed, such changes are already being made in the automotive industry ${ }^{2}$. Two exceptions are pressure vessel plate steels and ultrahigh strength 
steels. Annual U.S. consumption of ASTM A-387 steel grades used for pressure vessels, boilers, and heat exchangers is 8000 to 9000 tons. The common grades contain either 1.25 percent or 2.5 percent chromium which is required for high temperature strength, toughness, and resistance to hydrogen and elevated temperatures. There are no known chromium free substitutes. Ultrahigh strength steels used for aircraft landing gear all contain 0.8 to 1.00 percent chromium; no chromium free alternatives with adequate strength and fatigue resistance are known. For chromium conservation in both of these areas research is required. None is currently underway ${ }^{38}$. 
Specifications

Steel specifications--formalized agreements on compositional limits, reached by independent standards organizations, trade associations or professional societies involving sellers and buyers, etc.-may be a practical barrier to materials conservation in certain cases. Some specifications are imposed to assure properties directly, while others are associated with particular processing needs. When processes change some chemical specification can be lowered. A significant manganese conservation opportunity--possibly capable of saving 25 percent of current consumption--consists in bringing traditional manganese specifications in standard carbon steels into line with current low sulfur levels. The practice of using stainless grades with chromium concentrations up to twice that needed for corrosion resistance in service was mentioned previously. This problem is avoided generally when customers specify operational performance, and producers are free to determine the chemistry appropriate to the specified performance and their processing requirements 5 .

\section{Qualification}

The use of specific materials for certain areas that are safetyor defense-related is controlled by qualification through testing with approved procedures that simulate use. Materials used in the nuclear, power boiler and pressure vessel, and aerospace industries, especially aircraft engines, are generally covered by such qualification requirements. 
These qualification tests are generally both lengthy and expensive. They therefore inevitably tend to discourage innovation in materials use $^{39}$. Manufacturers in areas that cater to the private sector would sometimes prefer to ease qualification procedures to permit more rapid and less expensive innovation. Regulations governing qualification in these areas could usefully be reviewed in order to streamline qualification procedures.

\section{Composition of the National Defense Stockpile}

The technological advances described in the foregoing sections of this chapter are bringing about two pronounced changes in the raw materials requirements of the steel industry and those industries on which it depends for supply. These have implications for the National defense stockpile. The first change is in the general impurity level of the raw materials used in steel production; the second change is in the form of chromium imported for ultimate use by the steel industry.

The trend toward clean steels has led to a demand for purer raw materials. There is a particular desire to avoid unnecessary sulfur. Materials in the stockpile in general were purchased before these changed requirements and therefore are known or assumed to be less pure than what is now used in production.

On the other hand, the duplex processing procedures noted previously are able to remove such impurities. Where a number of impurities are present at levels higher than desired, more elaborate processing may be required than would be necessary for high quality raw materials. Nevertheless, the stockpile materials are generally believed to be 
useable with increased processing cost. In the event of a curtailment in steel raw materials, clean steels could be made via ladle metallurgy from the materials in the stockpile.

The prognosis for the country's ability to cope with a related stockpile question is not so bright, however. The rapidly increasing economic advantages of ferrochrome production in southern Africa are leading the industrialized countries of Europe, Asia, and the Americas to shift dramatically the types of material that they are importing. Ferrochromium imports are replacing the importation of chromite ore. We are thus losing our ability to process chromite ore into ferrochromium, and our stockpiles of chrome ore are therefore rapidly decreasing in utility for the emergency for which they were designed ${ }^{2}$.

The relative balance of different chromium-containing raw materials in the national defense stockpile need to be reexamined. Steps to do so have been initiated by the Department of Commerce in conjunction with the Federal Emergency Management Agency, the General Services Administration, the Department of the Interior, and the Department of Defense.

\section{Research}

The technical developments that will affect the use of chromium in most instances represent opportunities that will require research to realize. The research required is of two distinct types: short and long range. The types of technical problems addressed, the motivation for this activity, and thus the relative roles of private and public sectors differ markedly in the two cases. 
Short term research is directed toward immediate problems that require quidance from particular research results for rapid application on the production line. The private sector has an incentive to carry out materials research where it is needed to improve immediately the productivity of a production process or utilization by manufacturing industries. Where pressing needs develop, such as the need for highly corrosion resistant materials for use in hydrogen sulfide atmospheres, research has been initiated by the private sector ${ }^{39}$. Rapid increase in the price of a raw material also w1ll create such an incentive, and the response to the recent rapid increase in cobalt prices confirms this observation. Cobalt-free commercial alternatives to the use of cobalt in high speed tool steels were successfully developed and have given performance superior to that provided by cobalt ${ }^{35}$.

However, chromium and manganese are so relatively low in cost that cost effective alternatives have not been found. The continued low cost of these materials has not provided a strong incentive to continue the search for cost-effective alternatives in steel. Since the possibility of the loss of chromium supplies is relatively remote, the private sector has not made the investment in a continuing search for proven alternatives. Should access to chromium be lost suddenly, severe price and supply dislocations in the steel industry and industries that use steel would occur as they did in the recent markets for cobalt. Even in cases where relevant research has been carried out, it may be proprietary and hence not widely available ${ }^{11}$. The Federal Government is the only source of assured support for publicly available research results that can mitigate in advance severe price fluctuations in the event of a supply loss 32 . 
Investment in the proper long range research can help assure the achievement of the basic understanding essential to the satisfactory replacement of imported elements in existing alloys in the long run. Such research leads to alternatives with superior performance. However, long-term research is inherently expensive and is usually supported by Federal funding as well as by funding by industries with a large research base. Because the commercial incentive for such research is less immediate and because the benefits are frequently so fundamental that a single firm alone cannot recover research costs, the rationale for Federal funding is much stronger here than for short term research $2,38,43$. Examples of longer-term research that might affect the need for chromium and manganese are the effects of chemical composition on toughness 50 and the associated effects on toughness of lower levels of sulfur and oxygen obtainable through ladle metallurgy. The potential for the development of chromium-free carburizing steels is promising ${ }^{52}$. The replacement of chromium in stainless steel is another area of major importance. 


\section{CRITICAL MATERIALS AND PRODUCTIVITY}

The preceding sections of this chapter have described the technical changes that are taking place in the steel industry. Those parts of the U.S. industry that have been able to make the necessary investment in new technology ${ }^{6}$, have remained relatively competitive. The preceeding sections have also reviewed the influence that technological changes in the steel industry and in materials science more broadly are having on the raw materials requirements of the steel industry. These changes increase the elasticity of demand for specific raw materials by increasing the number of alternatives 54 .

In some cases such alternatives such as clean steels will be technically superior and cost-effective at present prices. These will tend to decrease the demand for imported raw materials both through improved performance, and through higher yields in processing. In other cases, alternative technologies will remain either technically disadvantageous or less cost-effective. Nevertheless, such technologies, if available, can mitigate any curtailment of supplies or escalation in price ${ }^{2}$.

The establishment of technical alternatives to current technology is therefore an important key both to increasing national productivity and to greater independence of foreign raw materials supplies 55 . Technical alternatives differ from strategic supply options. The other essential aspects of our comprehensive national strategy, such as stockpiles, play the role of an insurance policy. They would be critically important in an emergency, but only then. By contrast, technological alternatives 
can pay off whether or not a material supply emergency occurs. Indeed, technical alternatives can make the possibility of such an emergency less likely.

As detailed in this chapter, the question of critical materials in the manufacture of iron and steel products has been reviewed from many angles, including the effect of process technology, recycling and resource recovery, substitution and various types of new technology. The main conclusion from this review is that, from a technical viewpoint, the most potent factor for diminishing critical material problems is a healthy domestic steel industry pursuing the research and capital formation required for the introduction of leading technology and modernization on a continuing basis. This conclusion rests on the fact that, through the introduction of new technology for processing, for recycling, and for achieving future requirements in respect to product properties, the amount of critical materials required can be progressively reduced through the more discriminating utilization of alloying elements. The resulting steels will perform better, have more uniform quality, and will cost less. We anticipate that chromium and manganese, because of their relatively low cost, will continue to be used and therefore continue to be the materials of greatest concern to the steel industry. In many, perhaps most cases, however, alternatives are available, albeit at substantially higher expense. Changes in cost structure are therefore far more likely than total loss of material capable of performing essential functions in our economy. Research, by providing improved alternatives, can mitigate the possible swings in price and the severity of loss of supply. 
1. American Iron and Steel Institute, "Steel 1981"

2. Bement, Arden L., "Technical Aspects of Critical Materials Use by the Steel Industry Vol. II," NBSIR 83-2679-2

3. National Materials Advisory Board Report 335, "Contingency Plans for Chromium Utilization", 1978

4. Dennis, William E., Remarks delivered at the Public Workshop, "Trends in Critical Materials Requirements for Steels of the Future; Conservation and Substitution Technology for Chromium," Vanderbilt University, October 4-7, 1982

5. Geiger, Gordon H., Vol. II this report, see reference 2

6. Richmond, Frank M., Testimony before the Subcommittee on Oversight and Investigations, Committee on Energy and Commerce, U.S. House of Representatives, Apri 1 23, 1982

7. Shao, Maria, Wall Street Journal, November 24, 55 (1982)

8. Moore, J. J., J. Metals, June, 39 (1982)

9. Robinson, George H., Vol. II this report, see reference 2

10. Wright, Peter H., Vol II this report, see reference 2

11. O'Neil, Dennis B., Vol II this report, see reference 2

12. Cutler, Herschel, Vol II this report, see reference 2

13. K. K. Kappmeyer, private communication

14. Chandler, Harry E., Baxter, Donald F., \& Kruger, Leonard G., Metal Progress, January, 220 (1982)

15. Cordy, James T., Vol II this report, see reference 2

16. March, Eugene A., quoted in Metal Producing, January, 46 (1982)

17. Korchynsky, Michael, Paper delivered at the Public Workshop "Trends in Critical Materials Requirements for Steels of the Future;

Conservation and Substitution Technology for Chromium, "Vanderbilt University, October 4-7, 1982

18. Brunner, Lewis, Vol II this report, see reference 2

19. National Bureau of Standards \& Battelle Columbus Laboratories, "The Economic Effects of Fracture in the United States," in press, 1982

20. "Process Control Sensors for the Steel Industry," sponsored by the American Iron and Steel Institute, the Defense Advanced Research Projects Agency, and the National Bureau of Standards, July 22-28, 1982

21. Asphahani, Aziz I., Vol II this report, see reference 2

22. Gaugh, Robert R., Vol II this report, see reference 2

23. Moore, Peter G., Vol II this report, see reference 2

24. Duncan, Ronald N., Vol II this report, see reference 2

25. Skelly, James T., Vol II this report, see reference 2

26. Wood, William G., Vol II this report, see reference 2

27. Kachik, Edward A., Vol II this report, see reference 2

28. Hubble, David E., \& Kappmeyer, K. K., Vol II this report, see reference 2

29. Regan, R. J., Iron Age, 221(10), 30-33 (1978)

30. Joseph, Robert W. , private communication

31. Rawlings, J. W. , Conference sponsored by Business Week and Aviation Week, October 30, 1981 
32. Lula, R. A., and Bangaru, R., Vol II this report, see reference 2

33. National Material Advisory Board Report 391 "Tantalum and Columbium Supply and Demand Outlook," 1982.

34. U.S. Bureau of Mines, Mineral Commodity Summaries, 1982

35. Haswell, W. T., "Conservation and Substitution Technology for Critical Materials, NBSIR 82-2495, Vol. I, Paper No. 16

36. "Conservation and Substitution Options for Critical Materials," Vanderbilt University, June 1981

37. National Materials Advisory Board Report 374, "Manganese Reserves and Resources of the World and Their Industrial Implications," 1981.

38. Ault, R. T., Vol II this report, see reference 2

39. Kochera, John W., Vol II this report, see reference 2

40. Houze, Gerald L., Jr., Vol II this report, see reference 2

41. Jatczak, C. F., Vol II this report, see reference 2

42. Sikka, Vinod K., Vol II this report, see reference 2

43. Heger, James J., Vol II this report, see reference 2

44. Simenz, Rod F., Vol II this report, see reference 2

45. "Third Conference on Rapid Solidification Processing: Principles and Technologies," sponsored by the Defense Advanced Research Projects Agency, the Office of Naval Research, the Army Research Office, Air Force Wright Aeronautical Laboratory, and the National Bureau of Standards, December 6-7, 1982

46. Liu, C. T., and Koch, C. C., Vol II this report, see reference 2

47. Banerji, Samir K., Vol II this report, see reference 2

48. Wang, R., and Rapp, R. A., Vol II this report, see reference 2

49. Janowak, Jay, Vol II this report, see reference 2

50. Breen, Dale H., Vol II this report, see reference 2

51. Keith, Carl J., Vol II this report, see reference 2

52. Diesburg, D. E., Eldis, G. T., and Lander, H. N., Vol II this report, see reference 2

53. Jones, Brian L., Vol II this report, see reference 2

54. Swager, William, private communication

55. Gray, Allen G., Vol II this report, see reference 2 
BIBLIOGRAPHIC DATA

SHEET (See in struction S)

1. PUBLICATION OR
REPORT NO.
NBSIR $83-2679-1$

2. Performing Organ. Report Noy 3. Publication Date

April 1983

4. TITLE AND SUBTITLE

Technical Aspects of Critical Materials Use by the Steel Industry

Volume I: Summary Report

\section{5. $\operatorname{AUTHOR}(S)$}

R. Mehrabian, J. McKinley, B. Steiner and K. Bhansali

\begin{tabular}{l|l}
\hline 6. PERFORMING ORGANIZATION (If joint or other than NBS, see in structions) & 7. Contract/Grant No.
\end{tabular}

NATIONAL BUREAU OF STANDARDS

DEPARTMENT OF COMMERCE

WASHINGTON, D.C. 20234

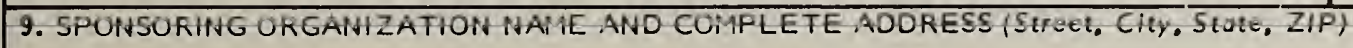

8. Type of Report \& Period Covered

10. SUPPLEMENTARY NOTES

[Document describes a computer program; SF-185, FIPS Software Summary, is attached.

11. ABSTRACT (A 200-word or less factual summary of most significant information. If document includes a significant bibliography or literoture surve.y, mention it here)

This report reviews technical opportunities for research in process improvement and in alternative materials development that would reduce U.S. dependency in critical materials.

The advanced technologies reviewed here, in addition to their implications for critical materials conservation represent trends leading to better quality, lower cost steel products, and therefore they may contribute positively to the industry's more immediate concern for improved markets.

The Summary Report draws extensively on material presented at a public workshop sponsored jointly by the National Bureau of Standards, Bureau of Mines, Army Research office, and Vanderbilt University. The workshof "Critical Materials Requirements for Steels of the Future; Conservation and Substitution for Chromium," was held at Vanderbilt University, October 4-7, 1982; it featured 44 presentations by technical authorities from steel producing and using industries. This material is presented in Volumes II A, and II B.

12. KEY WORDS (Six to twelve entries; alphabetical order: capitalize only proper names; and separate key words by semicolons) Advance coatings; alternative materials; chromium; processing; steel; strategic materials.

13. AVAILABILITY

Unlimited

LX For Official Distribution. Do Not Release to NTIS

$\square$ Order From Superintendent of Documents, U.S. Government Printing Office, Washington, D.C. 20402.

14. NO. OF

PRINTED PAGES

Order From National Technical Information Service (NTIS), Springfield, VA. 22/6I

15. Price 




